\title{
Research on the Influence of Psychological Capital on College Students' Academic Achievements
}

\author{
Dan Chen \\ Nanjing University of Finance and Economics Hongshan College \\ Nanjing, China
}

\begin{abstract}
Based on the perspective of psychological capital, this study takes the students of Suqian College as the research object, adopts the questionnaire survey method and mathematical statistics method, and uses the "psychological capital questionnaire for college students" and the "academic achievement scale for college students" to Investigate college students of randomly selected 500 students. Through the analysis of the data obtained by SPSS statistical analysis software, the research on the relationship between college students' psychological capital and academic achievement draws two conclusions: First, there is a difference in the population variables of psychological capital and its sub-dimensions and academic achievements and their sub-dimensions in gender, grade, specialty, student source, whether it is the only child. Second, there is a significant positive correlation between the psychological capital of college students and their various factors and their academic achievements and their various factors.
\end{abstract}

Keywords-college students; psychological capital; academic achievement; influence mechanism

\section{INTRODUCTION}

With the advent of the era of knowledge economy, higher education has become an important way to cultivate talents. Under the environment of increasingly fierce social competition and increasing employment pressure, college students, as the creative subject of the future of knowledge economy, how to overcome the negative factors in the learning process and improve their academic achievements have become the focus of colleges and universities. The concept of positive psychological capital has not entered China for a long time. If this concept is related to the academic achievements of college students and explores the relationship between them, it will provide a lot of help in improving the self-improvement of college students and the guidance of educators to college students.

\section{STUDY VARIABLES AND VARIABLE RELATIONSHIPS}

Psychological capital is the positive psychological quality of people's potential inner feelings, such as self-confidence, optimism, strength, diligence, progress, open-mindedness, tolerance, and gratitude. Professor Fred Lussans, the founder of the theory of psychological capital, and the famous American management scholar, defined it as: first, its nature is a positive psychological state, and secondly it is manifested in the development and growth of human individuals [1]. Obviously, the bearing of psychological capital is a human individual, and must conform to the characteristics of the state class, which are positive and positive emotions and advantages. Although the research and development of psychological capital is directed at individuals, individuals must be placed in the whole. In a group, emotions will affect each other, smiles can be transmitted, and happiness can be shared. Therefore, the overall psychological capital is greater than the sum of the individual's psychological capital, and synergies are generated through the complementarity of advantages, so that the overall performance is more greatly improved than the individual performance.

Academic achievement is skill and knowledge, which can be achieved through training and learning. It is a relatively clear learning outcome limited to a certain extent. Each person's level of academic achievement may vary, but each individual can improve his or her academic achievement through his own efforts. In 2004, Yao Benxian proposed the definition of academic achievement, which is an overall evaluation of the performance of college students' academic dedication, interpersonal promotion and learning performance in a certain period, including overall quality, comprehensive ability and academic achievement. With the advancement and maturity of research, the current definition of academic achievement is more reasonable and comprehensive. For example, in 2011, Wang Yanfei and other studies defined academic achievement as the result of the weighted summation of the attitudes, learning behaviors and learning outcomes of college students in a certain period of time [2].

Through the relevant literature analysis, the research on the psychological capital of college students and the academic achievements of college students is carried out. In this paper, the research variables are set. The five elements of psychological capital, including interest, resilience, optimism, gratitude and self-efficacy, are set as independent variables, that is, influencing factors. The academic achievement, including academic dedication, task performance, interpersonal promotion and total performance, are set as the dependent variable, that is, the consequence factor. Psychological capital consists of five dimensions as independent variables, and academics contain four dimensions as dependent variables. The relationship mechanism and variable relationship diagram are as follows: 


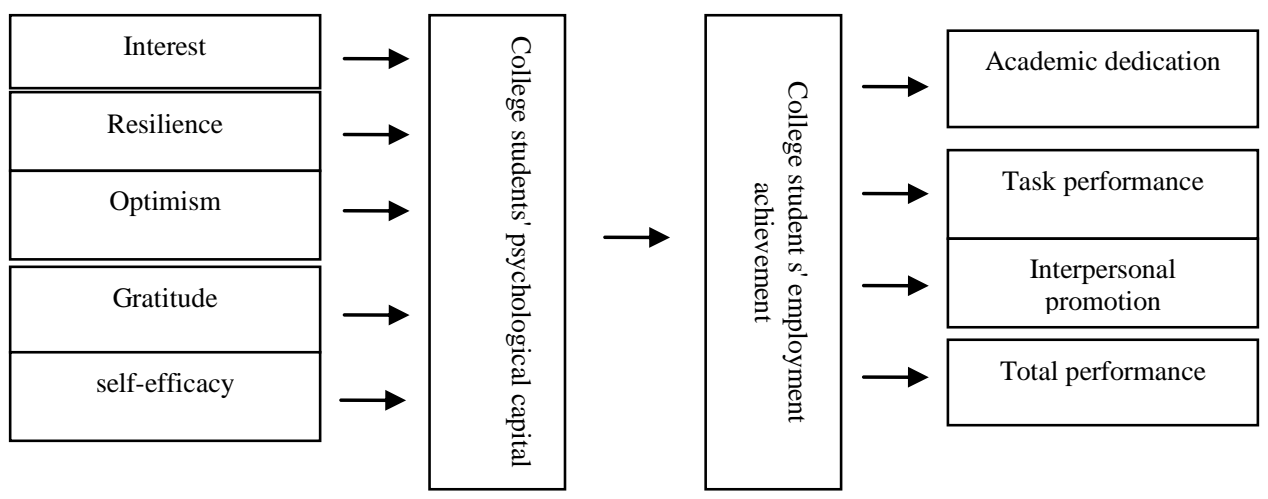

Fig. 1. Variable relationship diagram.

\section{THE MEASUREMENT TOOLS OF THE STUdY}

This study uses the "psychological capital questionnaire for college students" compiled by Xiao Wen in 2010 to measure the current psychological capital status of students in Suqian College. The scale includes a total of 29 self-evaluation projects, including five dimensions: interest, resilience, optimism, gratitude, and self-efficacy. The scale is scored on a scale of $1-5$, with 1 indicating "completely non-conformance" and 5 indicating "complete compliance". The Cronbach $\alpha$ coefficients of the five dimensions in the scale are between 0.81 and 0.89 , and the split-half reliability is between 0.82 0.88 , which has good reliability and validity. $\mathrm{Wu}$ Shuangshuang revised the "academic achievement scale for college students" in 2013. The scale includes 19 selfevaluation projects, which consist of four factors: academic dedication, task performance, interpersonal promotion and total performance. The scale has good structure and reliability and is suitable for measuring the academic achievement level of college students. It can effectively evaluate the academic achievement of college students and has stability and reliability. The correlation coefficient between the four factors in the scale is between 0.480 and 0.697 , and there is a moderate correlation. The correlation coefficient between each factor and the total score of the scale is between 0.731-0.905, which is very high [3]. In line with psychometric standards, the scale has a good homogeneity.

\section{RESEARCH SAMPLES AND DATA}

This study obtained first-hand data and original data by issuing the "Psychological Capital Questionnaire for College Students" and the "Academic Achievement Scale for College Students". The questionnaire surveyed students from the first to fourth year of Suqian College. The sample covers the three major categories of liberal arts, science, and engineering. A total of 500 questionnaires were distributed and 481 were returned, of which 470 were valid questionnaires, and the effective recovery rate was $94 \%$. The basic situation of the sample is shown in "Table I":

TABLE I. BASIC SITUATION OF THE SAMPLE

\begin{tabular}{lllllll}
\hline & & Liberal arts & \multicolumn{2}{c}{$\begin{array}{c}\text { Subject } \\
\text { Science }\end{array}$} & Engineering & Total \\
\hline \multirow{3}{*}{ Gender } & \multirow{3}{*}{ Male } & Count & 30 & 82 & 134 & 246 \\
& & Ratio (\%) & $6.38 \%$ & $17.45 \%$ & $28.51 \%$ & $52.3 \%$ \\
& \multirow{3}{*}{ Total } & Fent & 144 & 39 & 41 & 224 \\
& & Ratio (\%) & $30.64 \%$ & $8.30 \%$ & $8.72 \%$ & $47.7 \%$ \\
& & Count & 174 & 121 & 175 & 470 \\
& & Ratio (\%) & $37.02 \%$ & $25.75 \%$ & $37.23 \%$ & $100 \%$ \\
\hline
\end{tabular}

In the basic part of the questionnaire, five items were investigated: gender, grade, major, from rural/urban, and whether they were only children. Among them, 246 were boys (52.3\%), 224 were girls $(47.7 \%) ; 174$ were liberal arts students (37.02\%), 121 were science students $(25.75 \%)$, and 175 were engineering students $(37.23 \%) ; 129(27.4 \%)$ in the freshman year, $112(23.8 \%)$ in the sophomore year, $123(26.2 \%)$ in the junior year, $106(22.6 \%)$ in the senior year, and 214 in the city $(45.5 \%))$, 256 rural people $(54.5 \%) ; 346$ only children (73.6\%), 124 non-only children $(26.4 \%)$. It has been verified that the proportion of each indicator in the selected sample is roughly the same as that of the students in Suqian College. The distribution characteristics of the sample are shown in "Table II": 
TABLE II. DISTRIBUTION OF DEMOgRAPHIC CHARACTERISTICS OF STUDENTS IN SUQIAN COLLEGE

\begin{tabular}{lllll}
\hline \multicolumn{1}{c}{ Project } & \multicolumn{1}{c}{ Category } & Number of People & Percentage & Total \\
\hline Gender & Male & 246 & $52.3 \%$ & 470 \\
& Female & 224 & $47.7 \%$ & 470 \\
Subject & Liberal arts & 174 & $37.02 \%$ & 470 \\
& Science & 121 & $25.75 \%$ & 470 \\
& Engineering & 175 & $37.23 \%$ & 470 \\
Grade & Freshman & 129 & $27.4 \%$ & 470 \\
& Sophomore & 112 & $23.8 \%$ & 470 \\
& Junior & 123 & $26.2 \%$ & 470 \\
Origin & Senior & 106 & $22.6 \%$ & 470 \\
students & Urban & 214 & $45.5 \%$ & 470 \\
Whether & Rural & 256 & $54.5 \%$ & 470 \\
child & Only children & 346 & $73.6 \%$ & 470 \\
\hline
\end{tabular}

\section{THE IMPACT OF PSYCHOLOGICAL CAPITAL ON THE ACADEMIC ACHIEVEMENT OF COLLEGE STUDENTS}

\section{A. Analysis of Variance of Psychological Capital and College Students' Academic Achievement in Demographic Variables}

Exploring the relationship between psychological capital and the academic achievement of college students, we can set the independent variables as grade, major, gender, origin of student, and only child. The dependent variable is psychological capital and academic achievement of college students, one-way analysis of variance are performed, and study whether there are differences in the factors of population variables and the factors and whether the differences are significant. The data obtained were analyzed by ANOVA with SPSS19.0. The results of variance analysis confirmed that the larger the $\mathrm{F}$ value, the greater the degree of difference. When $\mathrm{F}>1$, and $0.01<\operatorname{sig}<0.05$, $\mathrm{F}$ had a statistically significant difference; when sig $<0.01, \mathrm{~F}$ had a statistically significant difference.

TABLE III. ANALYSIS OF VARIANCE OF PSYCHOLOGICAL CAPITAL AND COLLEGE STUdENTS' ACADEMIC ACHIEVEMENT IN THE DEMOGRAPHIC VARIABLE GRADE

\begin{tabular}{|c|c|c|c|c|c|c|}
\hline & & Square s & df & Mean square & & Significance \\
\hline \multirow[t]{3}{*}{ Psychological capital } & Inter-group & 5971.726 & 3 & 1990.575 & 4.789 & .003 \\
\hline & Intra-group & 193685.272 & 466 & 415.634 & & \\
\hline & Total & 199656.998 & 469 & & & \\
\hline \multirow[t]{3}{*}{ Academic achievement } & Inter-group & 1093.265 & 3 & 364.422 & 1.490 & .216 \\
\hline & Intra-group & 113942.116 & 466 & 244.511 & & \\
\hline & Total & 115035.381 & 469 & & & \\
\hline \multirow[t]{3}{*}{ Interest } & Inter-group & 238.614 & 3 & 79.538 & 3.839 & .010 \\
\hline & Intra-group & 9655.471 & 466 & 20.720 & & \\
\hline & Total & 9894.085 & 469 & & & \\
\hline \multirow[t]{3}{*}{ Resilience } & Inter-group & 254.993 & 3 & 84.998 & 6.194 & .000 \\
\hline & Intra-group & 6394.463 & 466 & 13.722 & & \\
\hline & Total & 6649.455 & 469 & & & \\
\hline \multirow[t]{3}{*}{ Optimism } & Inter-group & 418.864 & 3 & 139.621 & 4.765 & .003 \\
\hline & Intra-group & 13655.010 & 466 & 29.303 & & \\
\hline & Total & 14073.874 & 469 & & & \\
\hline \multirow[t]{3}{*}{ Gratitude } & Inter-group & 146.086 & 3 & 48.695 & 3.004 & .030 \\
\hline & Intra-group & 7553.906 & 466 & 16.210 & & \\
\hline & Total & 7699.991 & 469 & & & \\
\hline \multirow[t]{3}{*}{ Self-efficacy } & Inter-group & 323.728 & 3 & 107.909 & 5.214 & .002 \\
\hline & Intra-group & 9644.647 & 466 & 20.697 & & \\
\hline & Total & 9968.374 & 469 & & & \\
\hline \multirow[t]{3}{*}{ Academic dedication } & Inter-group & 155.496 & 3 & 51.832 & 3.807 & .010 \\
\hline & Intra-group & 6344.384 & 466 & 13.615 & & \\
\hline & Total & 6499.881 & 469 & & & \\
\hline \multirow[t]{3}{*}{ Task performance } & Inter-group & 175.211 & 3 & 58.404 & 1.376 & .249 \\
\hline & Intra-group & 19775.736 & 466 & 42.437 & & \\
\hline & Total & 19950.947 & 469 & & & \\
\hline \multirow[t]{3}{*}{ Interpersonal promotion } & Inter-group & 9.093 & 3 & 3.031 & .156 & .926 \\
\hline & Intra-group & 9059.250 & 466 & 19.440 & & \\
\hline & Total & 9068.343 & 469 & & & \\
\hline \multirow[t]{3}{*}{ Total performance } & Inter-group & 59.123 & 3 & 19.708 & 1.466 & .223 \\
\hline & Intra-group & 6264.632 & 466 & 13.443 & & \\
\hline & Total & 6323.755 & 469 & & & \\
\hline
\end{tabular}


"Table III" shows the variance of psychological capital and college students' academic achievement and the indicators of each dimension of the two variables in the demographic variable grade. It is known from the table that there are main effects of grades in psychological capital ( $\mathrm{F}=4.789$, $\mathrm{p}=0.003<0.05)$, interest $(\mathrm{F}=3.839, \mathrm{p}=0.01<0.05)$, toughness $(\mathrm{F}=6.194, \quad \mathrm{p}=0.000<0.001), \quad$ optimism $\quad(\mathrm{F}=4.765$, $\mathrm{p}=0.003<0.05), \quad$ gratitude $(\mathrm{F}=3.004, \quad \mathrm{p}=0.03<0.05)$, selfefficacy $(\mathrm{F}=5.214, \mathrm{p}=0.002<0.05)$, academic dedication $(\mathrm{F}=3.807, \mathrm{p}=0.01<0.05)$, namely, there are significant differences of grades in psychological capital, interest, optimism, gratitude, self-efficacy, and academic dedication; there is a very significant difference in optimism at the grade level. Then, using post-tests, the overall scores of senior students' psychological capital, interest, resilience, optimism, gratitude, self-efficacy, and academic dedication are significantly higher than those of freshmen, sophomores, and juniors. Although the difference of academic achievement $(\mathrm{F}=1.490, \mathrm{p}=0.216>0.05)$ in grades is not significant, there are still differences, which is reflected in the higher academic achievement of seniors than those in freshmen, sophomores and juniors.

In the same way, the variance of the psychological capital and the academic achievement of the university students and the gender indicators of the two variables in the gender of the demographic variables can be obtained. According to statistics, gender has a main effect in psychological capital $(\mathrm{F}=4.479$, $\mathrm{p}=0.035<0.05)$, interest $\quad(\mathrm{F}=9.973, \quad \mathrm{p}=0.002<0.05)$, and gratitude $(\mathrm{F}=14.040, \mathrm{p}=0.000<0.05)$, that is, the psychological capital and interest, are significantly different in grades, and there is a very significant difference in gratitude at the grade level. Further using the independent sample $t$ test, the scores of girls in psychological capital, interest, and gratitude were significantly higher than those of boys.

In the same way, the variance of psychological capital and academic achievement of college students and the various dimensions of the two variables in the demographic variables can be obtained. According to statistics, the professional has a main effect in total performance $(\mathrm{F}=4.750, \mathrm{p}=0.009<0.05)$, that is, there is a significant difference in the total performance. Then, after using the post-test, it is concluded that the overall score of the engineering students is significantly higher than that of the liberal arts students and science students; the overall scores of the liberal arts students are higher than those of the science students and engineering students in terms of psychological capital, interest, optimism, gratitude and interpersonal promotion. Engineering students' score higher in academic achievement, resilience, self-efficacy, and academic dedication than liberal arts students and science students; overall, science students' score higher on task performance than engineering students and liberal arts students.

In the same way, the variance of psychological capital and academic achievement of college students and the various dimensions of the two variables in the source of demographic variables can be obtained. According to statistics, origin of student has main effects on the student's academic achievement $(\mathrm{F}=6.918, \mathrm{p}=0.009<0.05)$, academic dedication $(\mathrm{F}=5.353, \quad \mathrm{p}=0.021<0.05), \quad$ task performance $(\mathrm{F}=5.769$, $\mathrm{p}=0.017<0.05) \quad$ interpersonal promotion $\quad(\mathrm{F}=4.310$, $\mathrm{p}=0.038<0.05)$, total performance $(\mathrm{F}=4.406, \mathrm{p}=0.036<0.05)$, namely there are significant differences of the origin of student in academic achievement, academic dedication, task performance, interpersonal promotion, total performance in students ground. Further, using the independent sample t-test, it is concluded that the student's academic achievement, academic dedication, task performance, interpersonal promotion, and overall performance are higher than those of rural students.

In the same way, it can be obtained the psychological capital and the academic achievement of college students and the variance of the two dimensions of each dimension indicator in whether the demographic variables are the only child. According to statistics, whether the only child has a main effect on gratitude $(\mathrm{F}=4.163, \mathrm{p}=0.042<0.05)$. That is to say, there is a significant difference of gratitude in whether or not there is an only child. Further using the independent sample $t$ test, the psychological capital and gratitude scores of non-only children are higher than those of only children.

Based on the above difference analysis, it can be known that there are differences in psychological variables and their sub-dimensions and academic achievements and their subdimensions in terms of gender, grade, major, place of origin, and whether or not they are only children.

\section{B. Analysis of the Correlation Between Psychological Capital and College Students' Academic Achievements}

Correlation analysis refers to the use of an indicator to analyze the existence of a certain degree of dependence between phenomena and phenomena. It cannot clarify the relationship between specific forms of variables. It is also impossible to infer the change of the other variable, which is an uncertain relationship[4]. Therefore, the independent variables and dependent variables are not necessarily determined in the correlation analysis, and the related variables can be random variables. According to the degree of correlation, the correlation can be divided into: irrelevant, incompletely related, and fully correlated; the difference in related properties can be divided into: positive correlation and negative correlation; the difference between related forms can be divided into: linear correlation and nonlinear correlation. In this paper, Pearson Correlation Analysis (Pearson Correlation Analysis) was used to analyze the independent variables and dependent variables in the study. The classical Pearson coefficient is a measure of the linearity of a variable with another variable. Its absolute value is in the interval $0-1$, and the absolute value of the correlation coefficient is proportional to the degree of correlation. Correlation coefficients indicate no correlation or very weak correlation in the 0-0.2 interval; weak correlation in the 0.2-0.4 interval; moderate correlation in the 0.4-0.6 interval; strong correlation in the 0.6-0.8 interval; and very strong correlation in 0.8-1.0 interval.

Firstly, the SPSS19.0 statistical analysis software was used to process the data obtained from the questionnaire, and the correlation analysis between psychological capital and college students' academic achievements was carried out. Listed in "Table IV" are the correlation coefficients for each study variable. The analysis shows that the sig value is 0.000 , 
indicating that the degree of significance is very high. The five positive psychological states of college students' self-efficacy, interest, optimism, gratitude and resilience and the total psychological capital scores are positively correlated with academic achievement and its factors, academic dedication, task performance, interpersonal promotion, and total performance, of which is very significant.

TABle IV. CORRElation ANAlysis of Psychological CAPITAl AND ACADEMic ACHIEVEMENT (N=470)

\begin{tabular}{|c|c|c|c|c|c|c|}
\hline & & $\begin{array}{c}\text { Academic } \\
\text { Achievement }\end{array}$ & $\begin{array}{c}\text { Academic } \\
\text { Dedication }\end{array}$ & $\begin{array}{c}\text { Task } \\
\text { Performance }\end{array}$ & $\begin{array}{c}\text { Interpersonal } \\
\text { Promotion }\end{array}$ & $\begin{array}{c}\text { Total } \\
\text { Performance }\end{array}$ \\
\hline \multirow{3}{*}{$\begin{array}{l}\text { Psychological } \\
\text { capital }\end{array}$} & Pearson relevance & $.522 * *$ & $.472 * *$ & $.445 * *$ & $.514^{* *}$ & $.340 * *$ \\
\hline & Significance(bilateral) & .000 & .000 & .000 & .000 & .000 \\
\hline & $\mathrm{N}$ & 470 & 470 & 470 & 470 & 470 \\
\hline \multirow[t]{3}{*}{ Interest } & Pearson relevance & $.485 * *$ & $.422 * *$ & $.416^{* *}$ & $.499 * *$ & $.304 * *$ \\
\hline & Significance(bilateral) & .000 & .000 & .000 & .000 & .000 \\
\hline & $\mathrm{N}$ & 470 & 470 & 470 & 470 & 470 \\
\hline \multirow[t]{3}{*}{ Resilience } & Pearson relevance & $.516^{* *}$ & $.504 * *$ & $.436 * *$ & $.470^{* *}$ & $.354 * *$ \\
\hline & Significance(bilateral) & .000 & .000 & .000 & .000 & .000 \\
\hline & $\mathrm{N}$ & 470 & 470 & 470 & 470 & 470 \\
\hline \multirow[t]{3}{*}{ Optimism } & Pearson relevance & $.464 * *$ & $.420 * *$ & $.395 * *$ & $.452^{* *}$ & $.311 * *$ \\
\hline & Significance(bilateral) & .000 & .000 & .000 & .000 & .000 \\
\hline & $\mathrm{N}$ & 470 & 470 & 470 & 470 & 470 \\
\hline \multirow[t]{3}{*}{ Gratitude } & Pearson relevance & $.435 * *$ & $.354 * *$ & $.381 * *$ & $.475^{* *}$ & $.251 * *$ \\
\hline & Significance(bilateral) & .000 & .000 & .000 & .000 & .000 \\
\hline & $\mathrm{N}$ & 470 & 470 & 470 & 470 & 470 \\
\hline \multirow[t]{3}{*}{ Self-efficacy } & Pearson relevance & $.496 * *$ & $.472 * *$ & $.419 * *$ & $.463 * *$ & $.340 * *$ \\
\hline & Significance(bilateral) & .000 & .000 & .000 & .000 & .000 \\
\hline & $\mathrm{N}$ & 470 & 470 & 470 & 470 & 470 \\
\hline
\end{tabular}

a. Note: ** indicates a significant correlation at the 0.01 level (both sides) with a significant probability level of correlation coefficient of 0.01 .

From the Pearson correlation coefficient in the "Table IV", the correlation between psychological capital and each subdimension and academic achievement and each sub-dimension is significantly correlated at the 0.01 level (two sides), and the correlation coefficient is between 0.251 and 0.522 . The five positive psychological states of college students, self-efficacy, interest, optimism, gratitude and resilience and psychological capital are significantly related to college students' academic achievement and academic dedication, task performance, interpersonal promotion and total performance. There is a significant positive correlation between the psychological capital of college students, with their various factors, and their academic achievements and their various factors.

\section{CONCLUSION}

Based on the two conclusions drawn from the research, it is concluded that the ways for college students to improve their mental capital and improve their academic achievements are as follows: 1. Set reasonable goals and improve self-efficacy; 2. Establish a good attitude and cultivate optimism; 3. Adjust the expectations, enhance resilience; Fourth, enhance motivation beliefs, establish hopes; Fifth, enhance the academic achievements of college students through psychological capital intervention. As a university teacher, the more advanced theory in the field of integrated management studies the academic achievements of college students from the perspective of psychological capital through SPSS data analysis, and draws the relationship between psychological capital and academic achievement of college students. It is of great practical significance and practical value to explore how college students can improve their academic achievements by improving their positive emotional factors.

\section{REFERENCES}

[1] Luthans F, Avolio B, Walumbwa F, and Li W. The psychological capital of Chinese workers: Exploring the relationship with performance $[\mathrm{J}]$. Management and Organization Review, 2005, 1: 247269.

[2] Wang Yanfei, Li Yunjian, Huang Yuexin. Research on the relationship between college students' psychological capital, achievement goal orientation and academic achievement [J] Higher Education Exploration 2011 (6) .

[3] Wu Shuangshuang. Understanding the relationship between social support, psychological capital and academic achievement of college students [D]. Shandong: Master's thesis of Shandong Normal University, 2013.1-3, 5-6.

[4] Xia Lihua, Xie Jinling. SPSS data statistics and analysis [M]. Beijing: Tsinghua University Press, 2014. 